sending me beautiful Eozöon pieces, I cannot say to them : According to my investigations also Eozöon canadenze must be regarded as a fossil species of foraminifera. I am convinced that both, like myself, had the honest intention to represent correctly the true nature of Eozöon. But they must own that in their descriptions they did not investigate so closely nor describe so minutely the shapes nor the relative positions of the various parts, as I have done in my treatise. If they had done this then I believe that the facts would have led them to the same conclusions which they forced upon me.

"If the Eozöon pieces from the Laurentian or 'Urgneiss' formation were really remains of an undoubted Eoraminifera species, then we should possess in them certain proofs that even during the formation of the most ancient strata of the earth's crust living beings occurred, and that the first organisms belonged to the lowest animals, by which biology and geology would have gained two highly important facts. Yet by the scientifically justified elimination of Eozöon from the domain of organic beings it is not proved that during the Laurentian period no living beings existed. Perhaps the graphite of the Urgnciss formation has its origin in organic beings.

"The proof that Eozöon is not a fossil rhizopod will perhaps for many persons take away an important link from the beautiful picture of the development of organic life upon the earth, which they may have drawn up for themselves. But the object of natural research does not consist in finding reasons for attractive conceptions about nature, but in knowing nature as it really is. Because only an insight into the real condition of nature can, in the long run, satisfy the scientific mind, which gives up as errors the most attractive hypotheses regarding the essence and action of nature, if in the face of newly discovercd facts they can no longer hold good, no matter whether these erroneous hypotheses may have reigned supreme for a long time previously, and may have been held to be the best conceptions of nature by the most eminent authorities.'

THE BLOWPIPE CONE-SPECTRUM, AND THE DISTRIBUTION OF THE INTENSITY OF LIGHT IN THE PRISMATIC AND DIFFRACTION SPECTRA

NOW that the optical properties of the blowpipe blue I cone have been so critically investigated, may I draw the attention of the readers of NATURE who are interested in the history of spectrum analysis, to what I think are the earliest experiments on that subject. They were published by me in 1848 . The memoir in which they are reprinted may be found in my "Scientific Memoirs." It contains a woodcut of the five rays, adjusted to a reference solar spectrum on page 64 , and another of the five images of the cone on page 69.

Let me also refer to some experiments I have recently made on the distribution of the intensity of light on the spectrum, by the aid of a new form of spectrometer, which depends on the well-known optical principle, that a light becomes invisible when it is in presence of another light about sixty-four times more brilliant.

In a memoir I am now publishing in the American Journal of Science, and which, I presume, will also appear in the Philosophical Magazine, I have described several modifications of this instrument. The following is one easily made :-

Remove from the common three-tubed spectroscope its scale-tube, and place against the aperture into which it was screwed a glass ground on both sides. In front of this arrange an ordinary gas light attached to a flexible tube, so that its distance from the ground glass may be varicd at pleasure. This light I cali the extinguishing light. On looking through the telescope-tube the field of view will be found uniformly illuminated, this being the use of the ground glass, the light of which is reflected from the prism. The brilliancy of the field depends on the distance of the extinguishing light from the ground glass, according to the ordinary photometric law.

Now, if another small gas flame be set before the slit of the instrument, on looking through the telescope its spectrum will be seen in the midst of a field of light. If the illumination of that field be made very brilliant, the spectrum will be extinguished; if feeble, all the coloured regions appear. By moving the extinguishing flame to proper distances, it will be found that the violet region is the first to disappear, the red the last. The yellow by no means resists longest, as it ought to do if it were the most brilliant. Hence it follows that in the prismatic spectrum, the red and not the yellow is the brightest ray.

If the cause of the increasing intensity of light in the prismatic spectrum, from the more to the less refrangible region, be the compression exercised by the prism on the coloured spaces, increasing as the refrangibility is less, we ought not to find any such peculiarity in the diffraction spectrum. In this the coloured spaces are arranged uniformly, and without compression in the order of their wave-lengths. An extinguishing light ought to obliterate them all at the same moment.

Having modified the common spectroscope by taking away its dark box, so that the slit-tube and the telescope tube could be set in any required angular position to each other, I put in the place of its prism a glass grating, inclined at $45^{\circ}$ to rays coming in through the slit. The ruled side of the grating was presented towards the slit. Now when the extinguishing flame was properly placed before its ground glass, the plane face of the grating reflected its light down the telescope-tube. In this, as in the former case, the spectrum of a small flame before the slit was seen in the midst of a field of light, the intensity of which could be varied by varying the distance of the extinguishing flame. It was now found that as the brilliancy of the extinguishing illumination increased, all the coloured spaces disappeared at the same moment, and on diminishing the illumination all the colours came into view at the same time. As long as the red was visible the violet could be seen.

From this it follows that in the diffraction spectrum the luminous intensity is equal in all the visible regions. In the memoirs now publishing I have applied these facts to the case of the spectrum distribution of heat.

University of New York JOHN WILLIAM DRAPER

\section{THE NEW THERMO-ELECTRIC LIGHT BATTERY}

$\mathrm{T}$ appears that a difficulty which it has long been the ambition of practical electricians to "overcome has at last been solved by M. Clamond. According to his statement, published in La Lumière Electrique, which is confirmed by the Count du Moncel, M. Clamond has succeeded in producing the electric light by means of his new thermo-electric battery. M. Sudré has also just published his design for a powerful thermo-electric battery, but we do not know whether this system has yet been put to any practical trial, whereas that of $M$. Clamond is now in actual use for the purpose of lighting certain factories in Paris. Full details of either system have not yet come to hand, so that it is only possible to state the general results at present obtained.

That heat could be transformed into electrical energy was first discovered by Seebeck in 1822, who found that an electric current was produced when the junction of two dissimilar metals was heated. Little use, however, was made of this discovery as a source of energy, owing to the feebleness of the current to which it gives rise, although it has been of great service since the time of Forbes and Melloni in the investigation of radiant heat. 
Prof. Bunsen, by the employment of different metals from those hitherto tried, found that he could increase the strength of the current, and M. Marcus, of Vienna, using alloys instead of simple metals for the positive and negative element, reduced the cost, while increasing the power of the battery. From a thermo-electric battery constructed on his principle, and also from a modified form, devised by Wheatstone, a current sufficiently strong to produce brilliant sparks, decompose water, \&c., was obtained. This was in 1865 , and but little progress has, until now, been made in this branch of science, with the exception of the improved forms of thermo-pile devised by Noë and by Messrs. C. and L. Wray, although the utilisation of heat-especially solar heat-for the production of electricity has long attracted the thoughts of many experimenters.

M. Clamond has for some time been at work upon the subject, and has so far succeeded that his thermo-electric battery has been employed since 1875 in M. Goupil's factories. These batteries are formed of iron, as the electropositive element, and an alloy of antimony and zinc for the negative; they are soldered together and arranged in a circular form, which can be built up as high as may be desired. The junctions of the metals are heated in the interior, but the electromotive force being proportional to the difference of temperature between the two extremities of each bar, it was necessary to make the bars long if a strong current was desired, and then the results were less satisfactory, owing to the increased internal resistance, the melting of the metals where they were soldered, \&c.

It is these hindrances to its extended use which M. Clamond has sought to obviate in his latest form of battery, which is composed of three distinct parts. The collector consists of a number of pieces of cast-iron so arranged that the heated air can circulate within them; a large surface is thus exposed to the heat, which the iron collects and communicates to the couples. The diffuser is the outside of the apparatus, and is made of sheets of metal. The thermo-pile proper is placed between these two, and is so arranged that the junctions of the metals are alternately at the temperature of the collector and the diffuser. Heat passes from the collector to the diffuser along these couples, which have no great length. In some forms which are very easily worked, a number of these couples are made into a flexible chain of any desired length, the extremities forming the poles of the battery. These chains, insulated from the other parts of the apparatus, can be united to each other by their free ends, so that a variety of couplings and combinations may be made. The model now in use for lighting a workshop in Paris is about $2 \frac{1}{2}$ metres high, and $\mathrm{I}$ metre in diameter, the exterior form being that of a polyhedron, to the sides of which the thermo-electric chains are attached; these are composed of small cubes of zinc and antimony joined together by plates of tin, to which they are soldered. Each half of the apparatus has 30 chains of 100 couples each, or 6,000 couples in all. To the outer surface of these chains are fixed the sheets of copper which form the diffuser or heat distributor.

Another model, made for the recent exhibition at the Albert Hall of the various systems of electric lighting, is square and much smaller, though of the same power.

Each half of the cylindrical battery can be made to supply a powerful electric light, while the square one can produce four lights of half the brilliancy. The electromotive force is, according to prolonged experiments, 2 I 8 volts, about equal to 120 Bunsen cells, while the resistance is $3 \mathrm{I}$ ohms. The large battery consumes only 9 or Io kilogrammes of coke an hour, and the smaller one even less, about $6 \frac{1}{2}$ kilogrammes. Moreover, the large exterior surface of the apparatus radiating its heat to the air around adapts it admirably for use in heating, as well as for lighting, and it can thus be made to serve the double purpose of giving warmth and light.
M. Sudré has also designed his thermo-pile with a view to obtaining one of small volume and having a low in ternal resistance; the other peculiarities of his battery consist in the manner in which one set of junctions are heated while the other set are cooled. $\mathrm{He}$ has also determined what is the best length for the bars forming the couples, in order that the necessary difference of temperature at the two extremities may be maintained, while yet making them as small as possible. This he finds should be from Io to 30 millimetres, according to the difference of temperature required. His manner of soldering together the two different metals is also novel and ingenious. In order that contact may be made with the whole surface of the bar, he cuts the plate, forming one metal, into the shape of a comb, twisting the teeth of this comb together, thus retaining a large surface, which yet has only a short length. The bars are fastened on to these twisted parts and the uncut part of the plate is coated with silicate of soda. The couples are formed in a mould in which the plates are fixed, the melted alloy is then run into the mould so that a block is formed of the alloy and the plates, firmly united. These chains or blocks are then placed between two plates, coated on one side with enamel or other electrically insulating substance; several chains may thus be arranged side by side, each chain being both calorically and electrically insulated. The parts of the chain are electrically insulated by the thickness of the plates, but heat can flow across the couples. The chains are next placed between a collector and a diffuser; the collector is ribbed if the source of heat be gas, in order to expose a greater surface. The diffuser is also ribbed for the same reason when the heat is merely allowed to radiate into the air. The whole battery is so arranged that the collectors form the inside of a circle within which the heated air is circulated.

\section{BIOLOGICAL NOTES}

THE BLOOD OF THE LOBSTER. - This liquid has been recently examined by M. Fredericq (Belgian Academy's Bulletin, No. 4), whose researches on the octopus were recently published. He finds in it as a rule two colouring matters, one blue, an albuminoid, coagulated by alcohol and heat, and apparently identical with the hamocyanine found in the blood of the octopus; the other of rose colour, and soluble in alcohol (not always present). The former loses its blue colour in vacuo, and recovers it when acted on by oxygen, and it contains copper. The blood of the lobster is rose when it is reduced; exposed to oxygen it takes a special tint, blue with reflected light (hæmocyanine), brown with transmitted light (rose matter). It coagulates spontaneously and therefore contains fibrine. The blood of certain Gasteropoda (Arion, Helix) is also found to contain hæmocyanine, whereas M. Fredericq has not found it in the Lamellibranchiata (Unio, Anodonta). The general conclusion is reached that in such different groups of invertebrates as cephalopod and gasteropod molluscs, crustacea and annelids, as well as in vertebrates, respiration is effected by means of metalliferous proteic substances (hæmoglobin, hæmocyanine, chlorocruorine) which form in the respiratory organ (branchia, lung) Iess stable oxygenated combinations. These latter are dissociated in their passage through the tissues. In invertebrates, the two great functions of the blood, respiration and nutrition of tissues, belong both to the plasma, the corpuscles having a quite accessory importance. In the blood of vertebrates there is, in this respect, a division of physiological work; the respiratory function devolves upon the corpuscles, the nutritive function on the plasma.

Annelids of THE Virginian COAST,-Mr. H. E. Webster has just published an account of the Annelida. Chætopoda which were collected in the summer months of 1874 and 1876 by the zoological expeditions sent out 